\title{
Assessing geographical variation on whistle acoustic structure of three Mediterranean populations of common bottlenose dolphin (Tursiops truncatus)
}

\author{
Gabriella La Manna $^{\mathrm{a}, *}$, Nikolina Rako Gospićc ${ }^{\mathrm{b}}$, Michele Manghi ${ }^{\text {c, }}$ \\ Marta Picciulin ${ }^{\mathrm{b}}$ and Gianluca Sarà ${ }^{\mathrm{d}}$ \\ ${ }^{a}$ MareTerra Onlus-Environmental Research and Conservation, \\ Regione Salondra 9, Alghero, Italy \\ ${ }^{\mathrm{b}}$ Blue World Institute of Marine Research and Conservation, \\ Kaštel 24, Veli Lošinj, Croatia \\ ${ }^{c}$ Nauta Ricerca e Consulenza Scientifica, Strada della Carità 8, Milano, Italy \\ ${ }^{\mathrm{d}}$ Dipartimento di Scienze della Terra e del Mare, Via delle Scienze ed. 16, \\ Università degli Studi di Palermo, Palermo, Italy \\ *Corresponding author's e-mail address: gabriella.lamanna@gmail.com
}

Received 31 October 2016; initial decision 5 February 2017; revised 20 April 2017; accepted 26 April 2017; published online ???

\begin{abstract}
Whistles are acoustic signals produced particularly during social interactions. Here, we compare whistles by bottlenose dolphins from three Mediterranean areas (Croatia, Sicily and Sardinia) to investigate the presence of acoustic divergence and to discuss the possible causes of variability. Whistle parameters differ significantly between populations, but PCA highlights that the majority of variability is due to a limited number of frequency parameters. Cluster and DFA show that the Croatian population is acoustically divergent from the western populations of Sicily and Sardinia. This divergence could be consistent with geographical isolation, and a possible genetic differentiation between populations, and/or an adaptation to the acoustic environment. Moreover, in a comparison of whistle parameters of different Mediterranean populations with those of previously published Atlantic populations, it was revealed that the Sicilian population was acoustically closer to Atlantic populations. Our results represent a contribution to identifying acoustically differentiated populations of bottlenose dolphins in the Mediterranean.
\end{abstract}

\section{Keywords}

acoustic behaviour, acoustic divergence, Mediterranean Sea, Cetacean. 


\section{Introduction}

Whistles are the most extensively studied type of sound produced by dolphins (Baron et al., 2008; Azzolin et al., 2014). These narrowband, frequency-modulated signals are emitted during dolphin social interactions and are used mainly for communication purposes (Steiner, 1981). Whistles are often used in acoustic comparative studies between different species and within a single species (Schultz \& Corkeron, 1994; Rendell et al., 1999; Rossi dos Santos et al., 2005; May Collado et al., 2007, 2008; Baron et al., 2008). Interspecific whistle differences are more related to the maintenance of reproductive isolation between sympatric species (Rendell et al., 1999) and diverse habitat characteristics (Papale et al., 2015), while the intraspecific whistle variations may be induced by various levels of separation between populations. Wang et al. (1995) found that geographic and social separation between populations may lead to variations in whistle structure of bottlenose dolphins (Tursiops truncatus). Dolphins in nearby areas may influence each other's whistles through mimicry during the periodic movements of individuals between adjacent regions (Wang et al., 1995; Janik \& Slater, 2000; Riesch et al., 2006). Alternatively, differences in whistle characteristics may reflect adaptation to the environmental heterogeneity within the species distribution range (Wang et al., 1995; Jones \& Sayigh, 2002; Baron et al., 2008). For example, several studies have demonstrated that changes in dolphin whistle characteristics (shifts in frequencies, changes in call duration and inflection rates) most likely represent an adaptation to conditions of increased ambient noise levels (Morisaka et al., 2005; Rossi dos Santos et al., 2005; Luis et al., 2014; Papale et al., 2014; Rako-Gospić \& Picciulin, 2016).

Understanding the genetic structure of a population across its distribution range usually requires testing on large samples. In the case of whales and dolphins, when genetic samples are not available, acoustic divergences may represent a proxy for the evaluation of geographic differences within a population (Delarue et al., 2009; Hoffman et al., 2015).

In this study, the whistle structure of the common bottlenose dolphin was compared between three geographic areas along the eastern and western Mediterranean Sea. Recent studies have suggested that the current genetic structure of common bottlenose dolphin populations in the Mediterranean Sea is a result of the stochastic distribution of Atlantic genetic variation during the recent post-glacial expansion (Gaspari et al., 2015). A weak boundary 
was found to divide the northern Atlantic and the western Mediterranean Sea populations. This suggests a relatively high level of continuing gene flow or a very recent division between the two populations (Natoli et al., 2005). Conversely, a strong boundary divides the western and eastern parts of the Mediterranean basin. Separated geographically by the Italian peninsula, the north Adriatic (eastern Mediterranean) common bottlenose dolphin population has shown to be genetically different from populations of the western Mediterranean and the North Atlantic (Gaspari et al., 2015; Natoli et al., 2005). The present study assesses whether acoustic divergence, measured through changes in whistle frequency and time variables, are consistent with geographic isolation and genetic differentiation between different bottlenose dolphin populations of the eastern and western Mediterranean Sea. As part of this study, we also compared bottlenose dolphin whistles from the western Mediterranean Sea and eastern central Atlantic Ocean, analysing results extracted from other published studies (Diaz Lopez, 2011; Papale et al., 2014). This provides a basis to assess the role of distance as a potential factor which causes whistle variation. The adaptation to the local acoustic environment, as alternative or concomitant cause of whistle variation, is also discussed.

\section{Methods}

\subsection{Study area}

Common bottlenose dolphin recordings were collected in three different Mediterranean areas: Cres and Lošinj Islands (Croatia-Northern Adriatic Sea, eastern Mediterranean Sea), Lampedusa Island (Strait of Sicily) and West Sardinia (western Mediterranean Sea; Figure 1).

Acoustic recordings in Croatia were made in an area of approximately $545 \mathrm{~km}^{2}$, extending over the eastern side of the Cres and Lošinj Islands. This area is characterised by numerous small uninhabited islands and islets, steep rocky shores, muddy sea bottoms, limestone reefs and sea depths that do not exceed $90 \mathrm{~m}$. The islands attract a large number of tourists each year, particularly during the summer when many of them reach these sites by recreational boats (Rako Gospić et al., 2013; Rako Gospić \& Picciulin, 2016). On average, this region appears to be part of the home range of about 200 common bottlenose dolphins (184 bottlenose dolphins; 95\% CI $=152-250 ; \mathrm{CV}=$ 0.17; Pleslić et al., 2015). Furthermore, it appears that common bottlenose dolphins form a relatively closed and conspicuous local population and that 


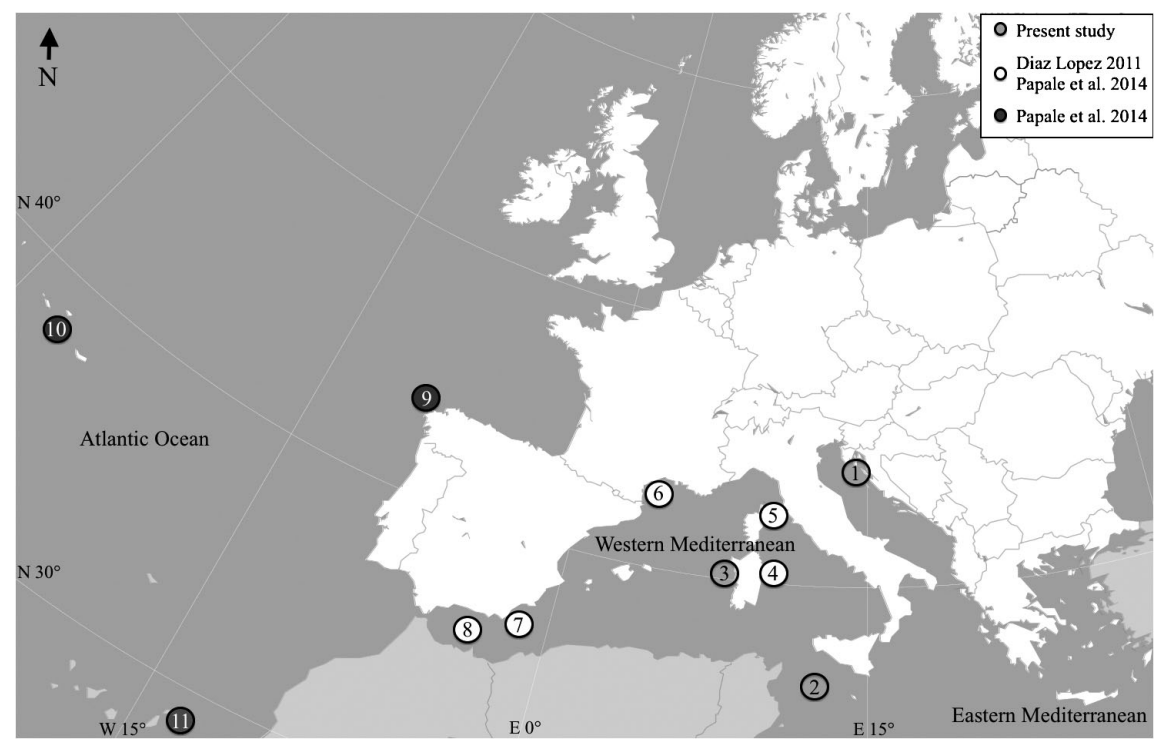

Figure 1. Study Area. Present study areas (grey circles): 1 (Croatia), 2 (Sicily) and 3 (West Sardinia). Western Mediterranean (white circle) from Diaz Lopez (2011) and Papale et al. (2014): 4 (East Sardinia), 5 (Tyrrhenian sea), 6 (Gulf of Lion, France), 7 (Almeria, Spain), 8 (Alboran Sea). Atlantic Ocean (dark circle) from Papale et al. (2014): 9 (Bay of Biscay, Spain), 10 (Azores Islands), 11 (Canary Islands).

movements between the core study area and adjacent areas represent displacements within the population range and should not be categorised as long-term migrations (Fortuna, 2006; Pleslić et al., 2015). The area was designated as a Site of Community Importance (SCI) of the NATURA 2000 network due to its importance for this dolphin population.

Lampedusa Island is located in the Strait of Sicily, a channel that connects the western and the eastern parts of the Mediterranean Sea, on the northern African continental shelf. Its topography consists of shallow banks along the Sicilian and Tunisian coasts, with water depth up to $200 \mathrm{~m}$. The very complex topography and circulation patterns of the Strait make it a highly productive area and a biodiversity hotspot (UNEP 2007). The study area is located around Lampedusa from the coast to $1.5 \mathrm{~km}$ offshore, and has a total area of $48 \mathrm{~km}^{2}$ and a maximum depth of $40 \mathrm{~m}$. The area includes a gradually decreasing rocky bottom and Posidonia oceanica meadows interspersed with sandy areas. The waters surrounding Lampedusa are characterised by highly concentrated heavy boat traffic, from July to September, when tourism is 
at its highest. Recreational motorboats (small motorised and/or inflatable rental boats and water-crafts) undertaking excursions around the island and dolphin-watching trips (both organised and accidental) represent the largest component of boat traffic in these waters (La Manna et al., 2010). Owing to the great abundance of fish, Lampedusa's waters are used by several trawlers from the mainland of the cross-border Mediterranean countries. The most recent estimation of the common bottlenose dolphin population size is 176 individuals ( $\mathrm{CI}=131-236$; Pulcini et al., 2013), but likely these dolphins are part of a larger population (Pulcini et al., 2010, 2013).

The western coast of Sardinia (West Sardinia) belongs to the Algero Provencal Basin, one of the most hydrodynamic areas of the western Mediterranean Sea. The study area is located along the coast of Alghero, and it extends for about $450 \mathrm{~km}^{2}$. The area includes a gradually graded rocky bottom, Posidonia oceanica meadows and detrital bottom with a depth not exceeding $70 \mathrm{~m}$. One of the main economic activities of this part of western Sardinia is sea-related tourism. This leads to an increase in boat traffic during summer. Small motorised and/or inflatable rental boats and bigger motor boats making excursions along the coast represent the largest component of boat traffic in these waters (La Manna et al., 2016). In this area the common bottlenose dolphin population size ranges between 80-120 animals, with at least 50\% which can be considered resident (La Manna, unpublished data).

To compare the whistles of the populations of these study areas with those from other populations of the Mediterranean Sea and the eastern central Atlantic Ocean, we selected studies that measured the same parameters with a comparable methodology (Figure 1). Thus, mean whistle parameters from east Sardinia (East Sardinia: Diaz Lopez, 2011), the western Mediterranean Sea (Tyrrhenian sea, Gulf of Lion, France; Almeria, Spain; Alboran Sea: Papale et al., 2014) and the eastern Atlantic Ocean (Canary Islands, Azores Islands, Bay of Biscay, Spain: Papale et al., 2014) were also considered in one of the statistical analyses.

\subsection{Field methodology and whistle analysis}

Acoustic recordings of bottlenose dolphins in Croatia were made between 2007 and 2009 (all year round), during the acoustic monitoring of underwater noise at ten predefined acoustic locations, in water with a depth between 40 and $90 \mathrm{~m}$, in Beaufort sea state conditions $<2$. Recordings were made from a rigid inflatable boat, at approximately $5 \mathrm{~m}$ depth, using a RESON TC 4032 
hydrophone (sensitivity $-170 \mathrm{~dB}$ re $1 \mathrm{~V} / \mathrm{Pa}$ ) connected to a Pioneer DC-88 DAT recorder calibrated with a signal of $100 \mathrm{mVRMS}$ at $2 \mathrm{kHz}$ (sampling rate $44.1 \mathrm{kHz}, 16$-bit).

Acoustic recordings in Lampedusa were made in 2006 and 2009 (all year round), by means of PAM (Passive Acoustic Monitoring) devices called RASP. Eight RASPs were used and equipped with programmable underwater acoustic recorders (M-Audio MicroTrack II; data format 16-24 bit WAV, sampling rate $48 \mathrm{kHz}$ ) and hydrophones with bandwidth between $10 \mathrm{~Hz}$ and $96 \mathrm{kHz}$ (Sensor Technology SQ2; sensitivity $-169 \mathrm{~dB}$ re 1V/1uPa). The recorders had a custom timer control board offering full programmability for recording times and intervals, and were equipped with hard disks offering from 4 to $32 \mathrm{~Gb}$ of memory per deployment (La Manna et al., 2013, 2014). RASPs were deployed on the bottom at a maximum depth of 35 $40 \mathrm{~m}$. These depths $(<40 \mathrm{~m})$ and distances from the coast $(<1.5 \mathrm{~km})$ were chosen to ensure common bottlenose dolphins were recorded in absence of visual identification. Despite the fact that the common dolphin (Delphinus delphis) is also present in the waters surrounding Lampedusa (Pace et al., 2015), in the present study area the species was never reported in literature or observed by the authors in over $400 \mathrm{~h}$ of observations between 2006 and 2009 (La Manna, pers. commun.). This is consistent with the preferred habitat of the common dolphin in the Mediterranean Sea (mean sighting depth > 150-200 $\mathrm{m}$ and average distance to the coast $>6 \mathrm{~km}$; Notarbartolo di Sciara \& Demma, 1994; Canadas \& Hammond, 2008; Benmessaoud et al., 2016; Gannier, 2016). After a pilot study, a duty cycle of equal intervals, 10:10 (i.e., $10 \mathrm{~min}$ of recordings every $20 \mathrm{~min}$ ) was selected. This duty cycle allowed the collection of $3.5 \mathrm{~h}$ per day. Since the RASP did not imply visual observation of dolphin groups, a dolphin sighting was defined as the sequence of consecutive recording files containing whistles. To reduce the risk of sampling the same group of dolphins more than once, the sequence of recordings had to be at least $3 \mathrm{~h}$ apart from the preceding one to be considered as a sighting of a different group. Acoustic recordings in West Sardinia were collected between 2013 and 2015 (all year round), by means of a hydrophone (Sensor Technology SQ26-08; sensitivity $-168.8 \mathrm{~dB}$ re $1 \mathrm{~V} / 1 \mathrm{uPa}$ ) with bandwidth between $10 \mathrm{~Hz}$ and $96 \mathrm{kHz}$ connected to an M-Audio MicroTrack II recorder (data format 16-24 bit WAV, sampling rate $48 \mathrm{kHz}$ ). Recordings were made from a $10 \mathrm{~m}$ motor boat at a depth between 5 and $10 \mathrm{~m}$, in Beaufort sea state conditions $<2$, in the presence of dolphin groups at a distance between 20 
Table 1.

Definition of whistle parameters used in the analysis.

\begin{tabular}{ll}
\hline Parameter & Definition \\
\hline $\begin{array}{l}\text { Start frequency } \\
\text { End frequency }\end{array}$ & $\begin{array}{l}\text { The beginning frequency of the whistle (in } \mathrm{kHz}) . \\
\text { The ending frequency of the whistle (in } \mathrm{kHz}) .\end{array}$ \\
$\begin{array}{l}\text { Min frequency } \\
\text { Max frequency }\end{array}$ & $\begin{array}{l}\text { The upper frequency bound of the whistle (in } \mathrm{kHz} \text { ). } \\
\text { Thelta frequency }\end{array}$ \\
$\begin{array}{l}\text { The difference between the upper and lower frequency limits of } \\
\text { the whistle (in } \mathrm{kHz}) .\end{array}$ \\
$\begin{array}{l}\text { The interval between the start and the end of the whistle (in sec). } \\
\text { Number of inflection } \\
\text { points }\end{array}$ & $\begin{array}{l}\text { The number of changes from positive to negative or negative to } \\
\text { positive slope in the contour of the whistle. }\end{array}$ \\
\hline
\end{tabular}

and $300 \mathrm{~m}$ and with the engine turned off. Before each recording, the recording system was calibrated by applying a sinusoidal voltage of $100 \mathrm{mV}$ RMS to the transducer input of the system by means of a signal generator.

During the aural and visual analysis of the spectrogram, each whistle with a signal-to-noise ratio sufficiently high to make it audible and completely visible in the spectrogram from their start to their end were classified as 'good whistles' and considered in the analysis (La Manna et al., 2013). Weak whistles, whistles overlapping with other sounds, whistles with no good definition of the contour and with no clear start and end points (defined as 'bad whistles') were discarded from the sample. Frequency parameters, number of inflection points and duration of the whistles (Table 1) were measured by visual inspection of the spectrogram (512/1024 point fast Fourier transform (FFT) and frame-length, Hamming window, 50\% overlap, $F_{\mathrm{s}}=24 \mathrm{kHz}$ ) using Raven 1.5 software (Cornell Laboratory of Ornithology, Ithaca, NY, USA). Each common bottlenose dolphin individual produces a whistle with a stereotyped contour, interpreted as an acoustic signature and used to identify and locate the individual (Caldwell \& Caldwell, 1965; Janik \& Sayigh, 2013); this signal is usually repeated in loop. To reduce the risk of collecting whistles from the same individual (pseudo-replication), each whistle that was recognised as a signature whistle by the observer was considered just once in the following analysis (La Manna et al., 2013).

\subsection{Statistical analysis}

We estimated descriptive statistics as mean, standard deviation, CV (coefficient of variation) and range of recorded whistles per area through $\mathrm{R}$ for 
Mac Os X. Different statistical methods were used to test if whistle parameters changed among the three study areas. First, a Multivariate Analysis of Variance (MANOVA) was applied using area (Croatia, Sicily and West Sardinia) as an independent variable and all whistle parameters as dependent variables. Since MANOVA requires multivariate normal distribution of the dataset, Mardia's multivariate normality test was applied. Homogeneity of the variance was also tested with Levene's test and homogeneity of the variance-covariance matrices with Box's $M$-test. Then, duration and number of inflection points were log-transformed to respect the assumptions of MANOVA. If the MANOVA was significant, a one-way ANOVA (Analysis of Variance) was conducted to test if a statistical difference existed among areas for each single whistle parameter. If the test showed significant inequality of the means, a Tukey's post hoc contrast was performed to compare each parameter between each pair of areas. A Principal Component Analysis (PCA) was conducted to isolate independent and uncorrelated whistle parameters. PCA converts a set of observations of possibly correlated variables into a set of values of linearly uncorrelated variables called principal components. The first principal component has the largest possible variance (that is, it accounts for as much of the variability in the data as possible), and each succeeding component, orthogonal to the preceding component, in turn has the highest variance possible. We used PCA to create a few key variables (resulting as a composition of many original variables) that characterise the variation in the multivariate dataset (Flury, 1988). Principal components scores were tested for normality (Shapiro-Wilk multivariate test), presence of outliers (Adjusted Quantile Plot), and homogeneity of the variance (Levene test). A hierarchical cluster analysis (using the average linkage method, Euclidian distance) with the whistle mean values of each group was performed to evaluate the similarity between the three study areas. To validate the result of the cluster analysis, a Discriminant Function Analysis (DFA) was applied to the mean values of each group to verify if whistles could be attributed to the correct study area. DFA is a multivariate technique for describing a mathematical function that will distinguish among predefined groups of samples. All the assumptions of the DFA (multivariate normality of the independent variables, adequate sample size) were respected. To evaluate the output of DFA leave-one-out cross-validation (jack-knifed validation) was applied. The procedure excludes one observation, formulates a discriminant function using the remaining data, and uses that function to classify 
the excluded observation. Jack-knife cross-validation should be preferred as validation techniques because it returns a mean estimate of the proportion of correctly classified individuals with a much lower variance, respect to other techniques (Dechaume-Moncharmont et al., 2011). 95\% CIs around discriminant rate were calculated to show DFA accuracy and to allow comparison among studies (Dechaume-Moncharmont et al., 2011). Finally, to evaluate the similarity between bottlenose dolphin populations of the Mediterranean Sea and Atlantic Ocean, following a methodology applied in other studies (Rossi-Santos \& Podos, 2005; May Collado \& Wartzok, 2008; Moron et al., 2015) a hierarchical cluster analysis (using the average linkage method, Euclidian distance) was performed. We used cluster groups based on the similarity of the mean values of each selected area: Croatia, Sicily, West Sardinia, East Sardinia, western Mediterranean Sea (Tyrrhenian sea; Gulf of Lion, France; Gulf of Vera, Spain; Alboran Sea) and eastern central Atlantic Ocean (Canary Islands; Azorre Islands; Bay of Biscay, Spain). For the last three multivariate statistics, we could not consider correlated variables, thus we excluded delta-frequency, since it is the result of the difference between minimum and maximum frequency. All multivariate statistics were run in $\mathrm{R}$ for Mac Os X.

\section{Results}

In Croatia a total of $2.6 \mathrm{~h}$ of recordings were collected over 29 days, from which we extracted 262 whistles classified as 'good whistles', belonging to 31 different groups. In Sicily a total of $119 \mathrm{~h}$ of recordings were collected over 34 days, from which we extracted 183 whistles belonging to 21 different groups. In West Sardinia a total of $10.25 \mathrm{~h}$ of recording were collected over 22 days, from which we extracted 166 whistles, belonging to 18 different groups. In each area, stereotyped whistles were considered only once, reducing the initial database of 870 whistles to that used for the analysis (611 whistles in total). The descriptive statistics of all parameters are illustrated in Table 2. CVs were higher for duration, number of inflection points and delta frequency, across all areas. In general, CVs were larger for all parameters of Croatia compared to Sicily and West Sardinia. MANOVA results showed that whistle parameters were significantly different between areas (Pillai's trace $\left.=0.52, F_{14,1206}=30.69, p<0.001\right)$. ANOVA results showed that all whistle parameters were significantly different between areas (Table 3). Post 


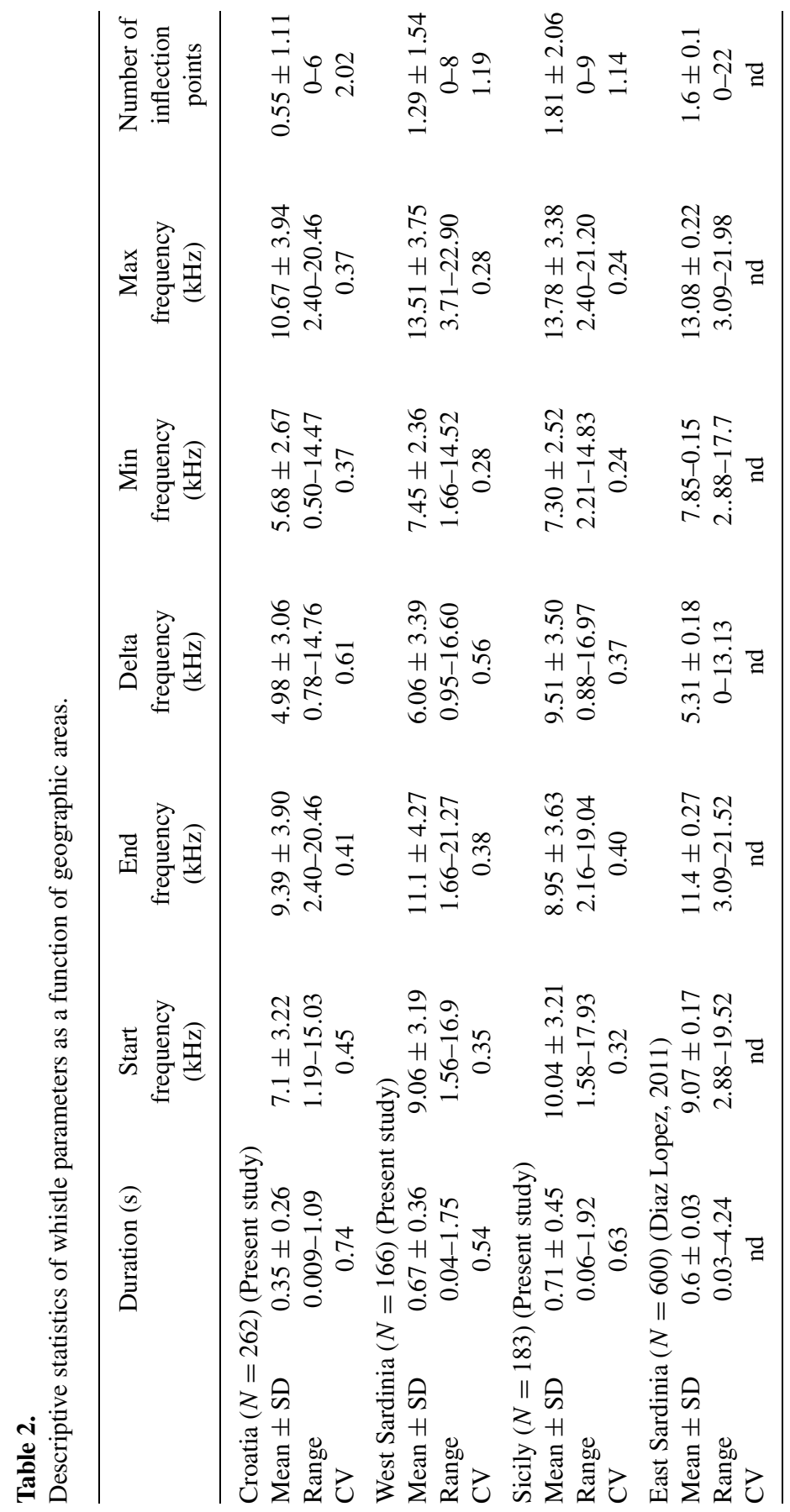


G. La Manna et al. / Behaviour (2017)

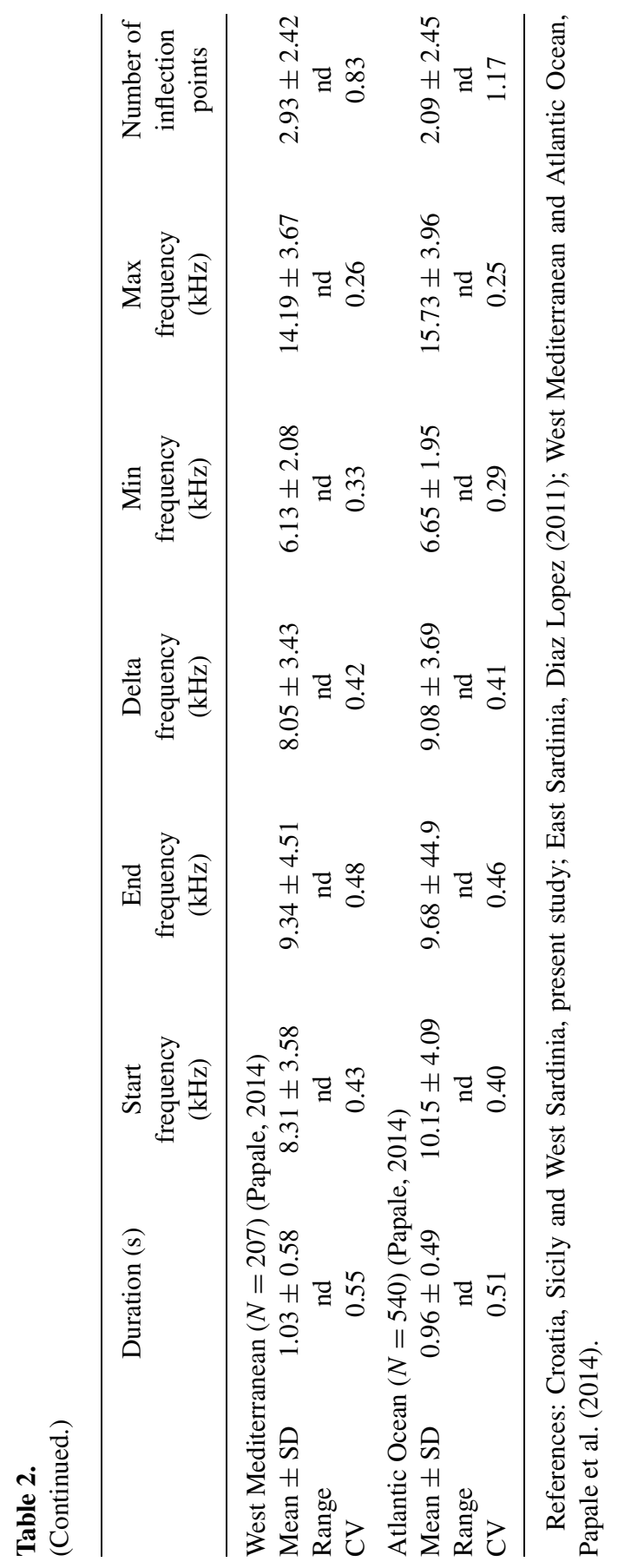


Table 3.

ANOVA output on whistle parameters.

\begin{tabular}{|c|c|c|c|c|c|c|}
\hline & & df & Sum sq (SS) & Mean sq (MS) & $F$ & $p$ \\
\hline \multirow[t]{2}{*}{ Duration } & Locality & 2 & 4.813 & 2.4067 & 81.14 & $<0.001$ \\
\hline & Residuals & 608 & 18.033 & 0.0297 & & \\
\hline \multirow{2}{*}{$\begin{array}{l}\text { Number of } \\
\text { inflection } \\
\text { points }\end{array}$} & Locality & 2 & 26.58 & 13.292 & 56.88 & $<0.001$ \\
\hline & Residuals & 608 & 142.07 & 0.234 & & \\
\hline \multirow[t]{2}{*}{ Start frequency } & Locality & 2 & 997 & 498.49 & 48.32 & $<0.001$ \\
\hline & Residuals & 608 & 6272 & 10.32 & & \\
\hline \multirow[t]{2}{*}{ End frequency } & Locality & 2 & 431.8 & 215.903 & 13.98 & $<0.001$ \\
\hline & Residuals & 608 & 9388.8 & 15.442 & & \\
\hline \multirow{2}{*}{$\begin{array}{l}\text { Delta } \\
\text { frequency }\end{array}$} & Locality & 2 & 2285.6 & 1142.8 & 105.63 & $<0.001$ \\
\hline & Residuals & 608 & 6578.1 & 10.82 & & \\
\hline \multirow[t]{2}{*}{ Min frequency } & Locality & 2 & 426 & 213.22 & 32.90 & $<0.001$ \\
\hline & Residuals & 608 & 3941 & 6.48 & & \\
\hline \multirow[t]{2}{*}{ Max Frequency } & Locality & 2 & 1341.9 & 670.96 & 48.24 & $<0.001$ \\
\hline & Residuals & 608 & 8456.7 & 13.91 & & \\
\hline
\end{tabular}

hoc comparison showed that: (i) start frequency, delta frequency and number of inflection points were significantly smaller in Croatia compared to Sicily and West Sardinia, and significantly different between the three areas (Tukey test, $p<0.001$ ); (ii) max frequency, min frequency and duration were significantly smaller in Croatia compared to Sicily and West Sardinia (Tukey test, $p<0.001$ ), while there was no difference between Sicily and West Sardinia (Tukey test, $p>0.05$ ); and (iii) end frequency was significantly larger in West Sardinia compared to Croatia and Sicily (Tukey test, $p<0.001$; Figure 2).

PCA showed that most variability was explained by PC1 (46\%) and PC2 (23\%; Table 4). PC1 was positively correlated with start frequency, max frequency, delta frequency, and min frequency, while PC2 was positively correlated with duration and number of inflection points and negatively correlated with end frequency (Figure 3).

The hierarchical cluster analysis showed the similarity of common bottlenose dolphin whistles across areas of the Mediterranean Sea based on mean values of whistle parameters from each group.

Cluster analysis grouped the 69 groups into 5 prevalent clusters: (i) a cluster with 6 groups from Croatia; (ii) a cluster with 19 groups from Croatia, 

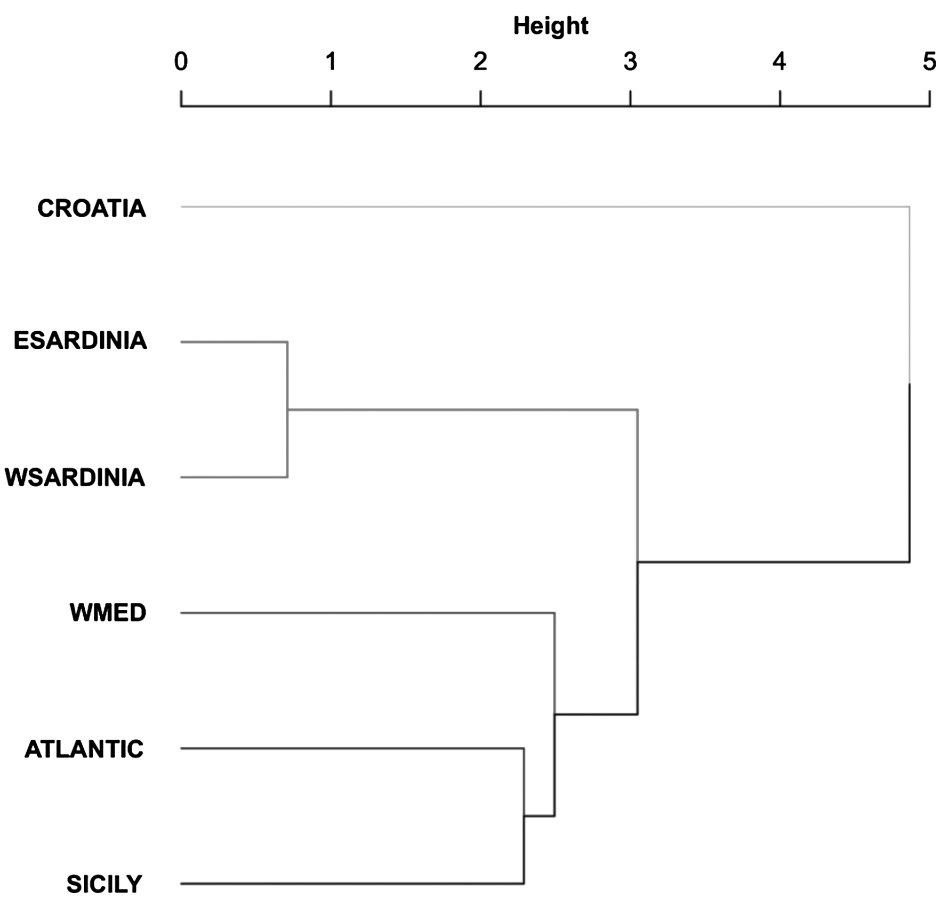

Figure 2. Mean \pm SE of whistle parameters as a function of geographic areas (Croatia, Sicily and West Sardinia).

Table 4.

PCA loadings.

\begin{tabular}{lcc}
\hline & PC1 & PC2 \\
\hline Max frequency & 0.519 & -0.011 \\
Start frequency & 0.425 & -0.113 \\
Delta frequency & 0.379 & 0.144 \\
Min frequency & 0.402 & -0.388 \\
End frequency & 0.346 & -0.384 \\
Duration & 0.276 & 0.570 \\
Number of inflection points & 0.223 & 0.586 \\
\% of variance & $46 \%$ & $23 \%$ \\
\hline
\end{tabular}

The first four values represent the largest loadings and show the variables that contribute most to each principal component. 


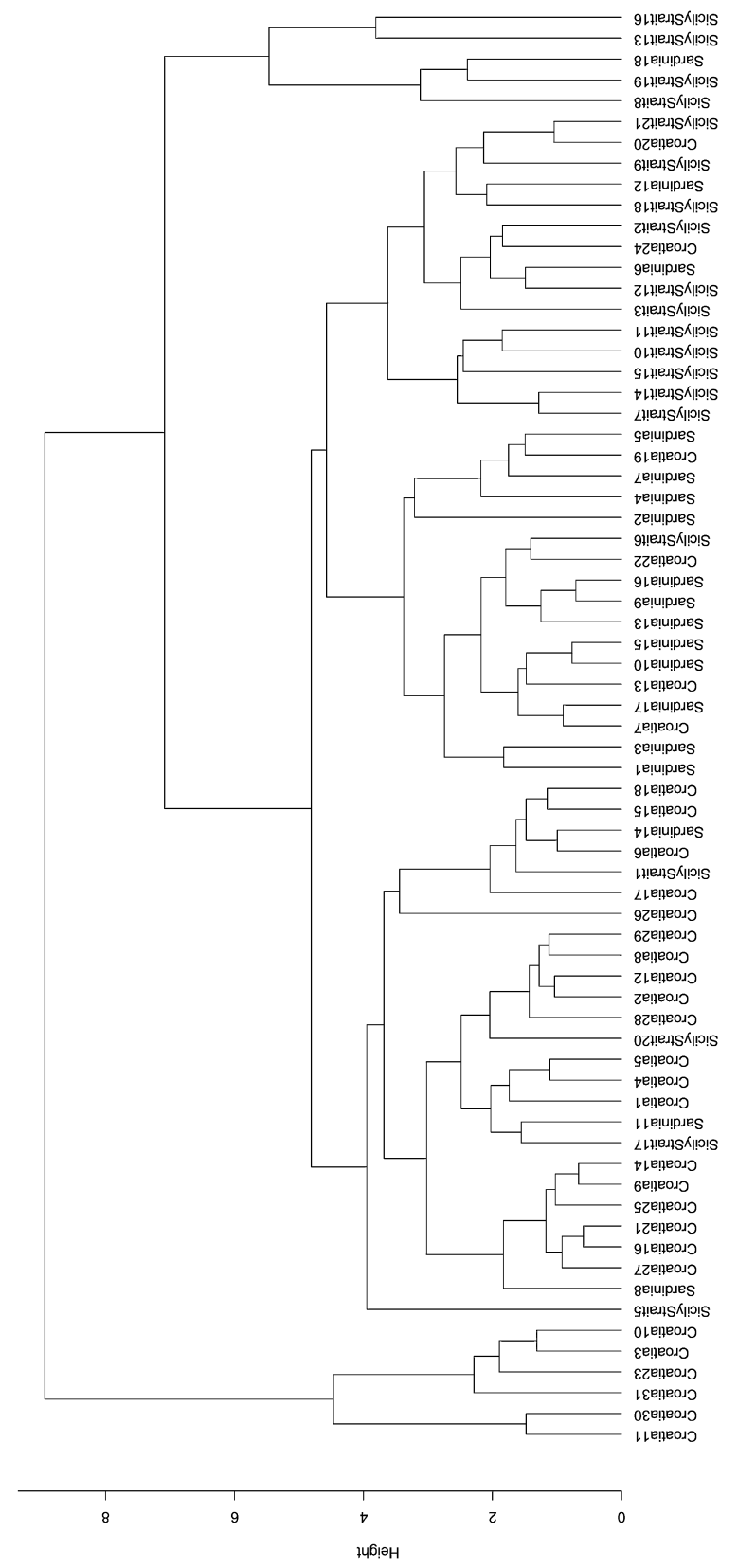

魚

$\dot{0}$

के $\frac{2}{60}$

흥

후

雳

$\stackrel{0}{0}$

ฮิ

हี่ 


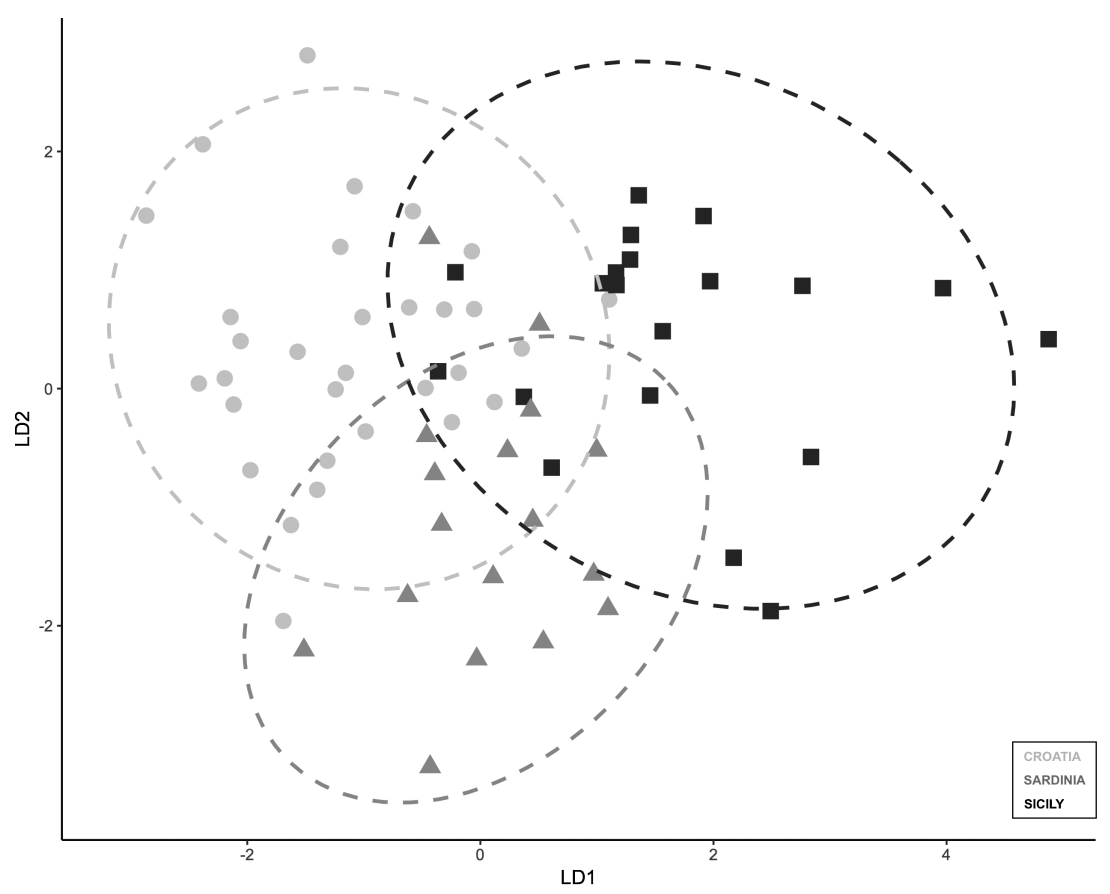

Figure 4. Result of the agglomerative cluster analysis for Croatia, Sicily, West Sardinia. The dendrogram groups the sites into clusters based on similarity in whistle parameters. The $y$ axis indicates the Euclidian distance for which sites are joined into higher-level clusters.

4 groups from Sicily and 3 groups from West Sardinia; (iii) a cluster with 12 groups from West Sardinia, 4 from Croatia and 1 from Sicily; (iv) a cluster with 11 groups from Sicily, 2 groups from West Sardinia and 2 groups from Croatia; (v) a cluster with 5 groups, 4 from Sicily and 1 from West Sardinia (Figure 4). To validate the results of the cluster analysis a DFA was performed. The DFA showed that 78\% (95\% CI: 67-86\%) of groups could be classified into the correct study area. In particular, $90 \%$ of the groups were correctly assigned to Croatia, $66 \%$ to Sardinia and $72 \%$ to Sicily (Table 5). The DFA plot (Figure 5) provided an overview of geographical variation in whistle parameters, showing a separate cluster of groups from Croatia, a separate cluster of groups from Sicily, a separate cluster of groups from Sardinia, and, finally, a mixed cluster of overlapping groups from all areas.

The last hierarchical cluster analysis performed on mean value of whistle parameters from different areas of the Mediterranean Sea and the eastern central Atlantic Ocean showed that: (i) whistles from the Croatian population 
Table 5.

Original and cross validated discriminant function analysis between Croatia, West Sardinia and Sicily.

\begin{tabular}{lccc}
\hline & Croatia & West Sardinia & Sicily \\
\hline Original & & & \\
$\quad$ Croatia & $94 \%$ & $3 \%$ & $3 \%$ \\
West Sardinia & $12 \%$ & $76 \%$ & $12 \%$ \\
$\quad$ Sicily & $14 \%$ & $5 \%$ & $81 \%$ \\
Cross-validated & & & \\
$\quad$ Croatia & $90 \%$ & $3 \%$ & $7 \%$ \\
$\quad$ West Sardinia & $17 \%$ & $66 \%$ & $17 \%$ \\
Sicily & $14 \%$ & $14 \%$ & $72 \%$ \\
& & & $78 \%$ (CI 67-86\%) \\
Overall predictive accuracy & & \\
\hline
\end{tabular}

formed separate clusters, being the least similar to all other areas; (ii) whistles from the Sicilian population were more similar to those of the Atlantic Ocean than to those of the Western Mediterranean; (iii) whistles from western and eastern Sardinian population were clustered together and resulted more similar to the western Mediterranean and Atlantic populations than to the Croatian population (Figure 6).

\section{Discussion}

The present study analysed whistle parameters recorded in three Mediterranean areas. In Croatia, West Sardinia and Sicily common bottlenose dolphin whistles showed a high intra-population variability in the duration and the number of inflection points, and a low acoustic variability in the frequency parameters, in accord with other studies (Wang et al., 1995; Morisaka et al., 2005; Papale et al., 2013). According to previous studies, duration and number of inflection points are whistle parameters that have been associated in order to provide additional information related to individual identities and/or emotional states (Steiner, 1981; Wang et al., 1995). Conversely, frequency parameters have been determined or restricted by some factors, such as the size of sound production organs and muscles, body size and group size and/or the environmental background noise levels (Wang et al., 1995; May Collado \& Wartzok, 2008). The present inter-population comparison high- 


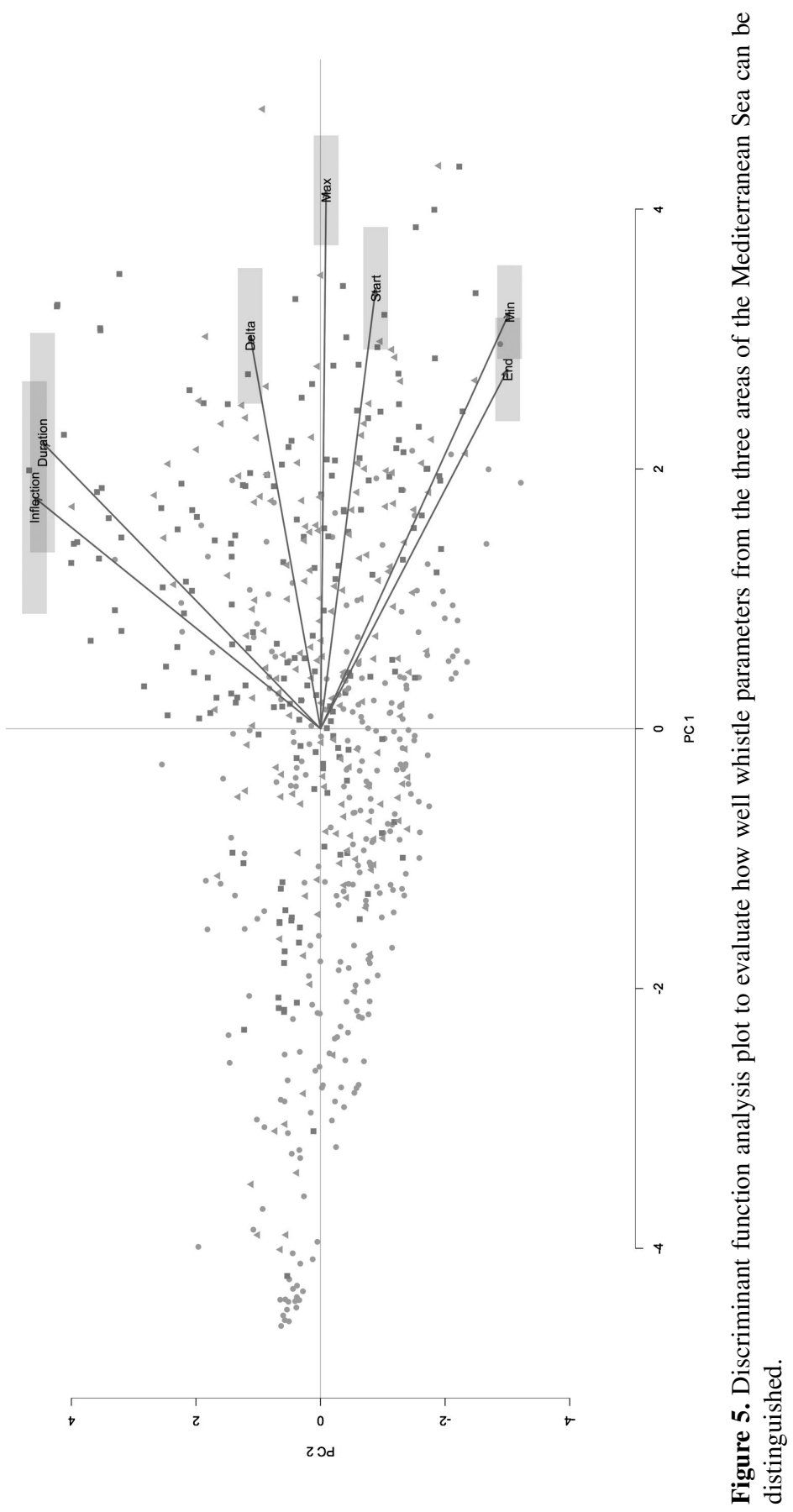



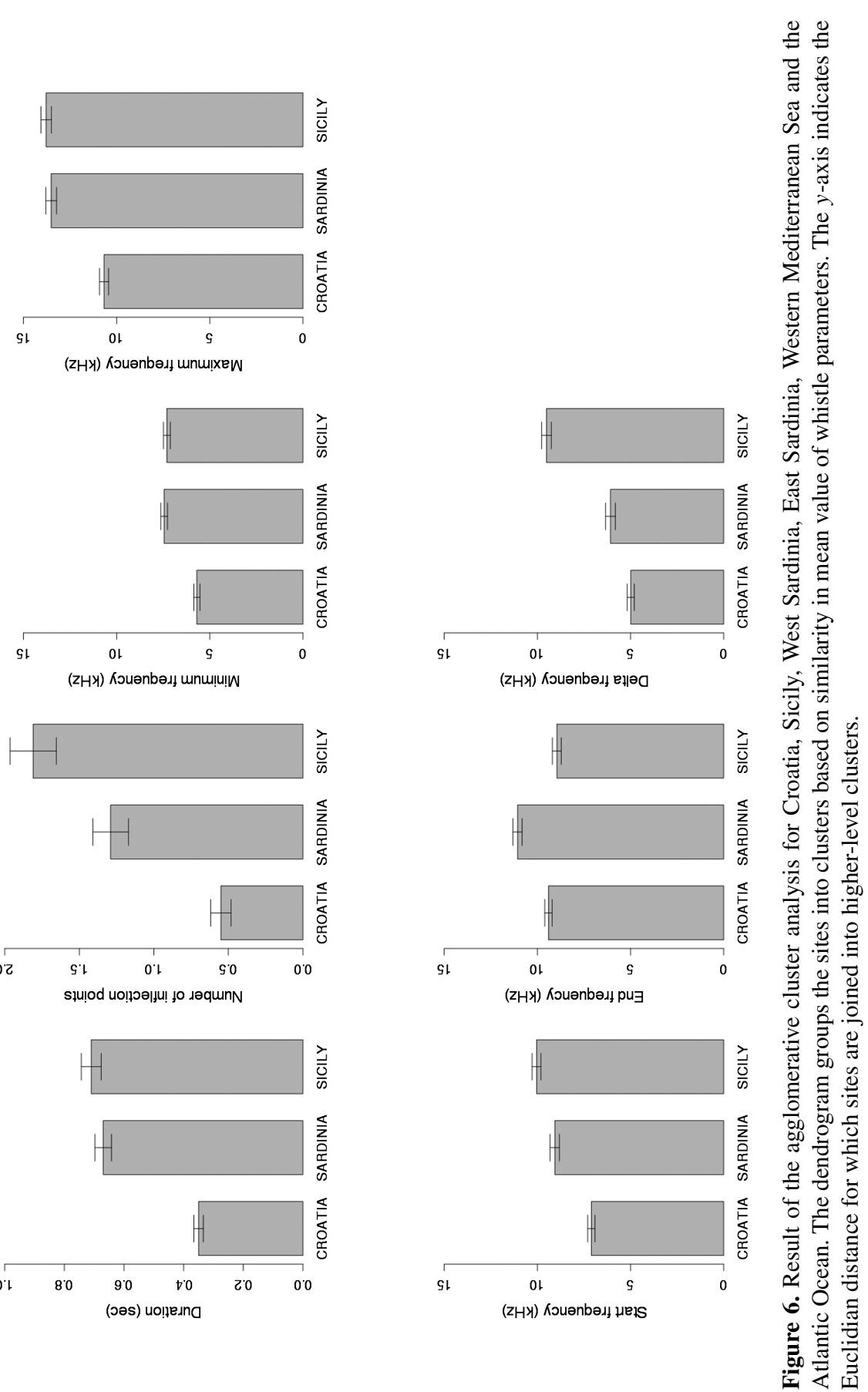
lighted a significant difference in common bottlenose dolphin whistle parameters between Croatia and the two other areas (Sicily and West Sardinia). The majority of variability between areas was due to frequency parameters. Although group size and behavioural states can induce whistle variation in dolphins (Quick \& Janik, 2008; Heiler et al., 2016), differences in frequency parameters are usually associated with variations between species or between populations (Azevedo et al., 2007; Azzolin et al., 2014). In fact, variations in frequency parameters have been observed between different bottlenose dolphin populations around the world (Wang et al., 1995; Azevedo et al., 2007; May Collado \& Wartzok, 2008; Papale et al., 2014). Finally, once also considering the other western Mediterranean (Tyrrhenian Sea, Gulf of Lion, Gulf of Vera and Alboran Sea) and Atlantic (Canary Islands, Azores Islands and Bay of Biscay) populations, we found a closer similarity between whistles emitted by dolphins living in Sicily and the Atlantic when compared to the western Mediterranean populations.

The acoustic divergences in the recorded whistle structures are consistent with geographic isolation and genetic differentiation between different common bottlenose dolphin populations of the eastern and western Mediterranean Sea (Natoli et al., 2005; Gaspari et al., 2015). Although no data exist on the genetic structure of common bottlenose dolphins sampled in Sicily and Sardinia, the eastern Mediterranean populations have already proved to be genetically different from those of the western Mediterranean (comprised of samples from north Africa, the Baleari Islands and the Tyrrhenian Sea) and the north Atlantic (Natoli et al., 2005; Gaspari et al., 2015). Evolution and maintenance of genetic divergence between the eastern and western Mediterranean have been related to differences in marine habitats that lead to site fidelity of the populations (Natoli et al., 2005; Gaspari et al., 2015). In this perspective, geographical isolation and genetic divergence evolved and maintained by different habitat conditions could explain the acoustic variations found between the Croatian and the more western populations of Sicily and West Sardinia. The DFA reflects a certain level of overlap in acoustic parameters across areas but it also indicates the presence of features that vary consistently across the range of our study areas, from the west to the east part of the Mediterranean. Whistles from Sicily and Sardinia were similar to each other but the distance of about $500-600 \mathrm{~km}$ between these two islands is beyond the known migratory range of the species in the Mediterranean Sea (on average $50 \mathrm{~km}$, maximum $427 \mathrm{~km}$; Gnone et al., 2011). Consequently, the 
similarities between these populations might possibly be attributable to biogeographic factors, reflecting that these two populations were more recently isolated. Conversely, the whistle parameters from Lampedusa Island (Sicily) are more similar to those of dolphins living in the Atlantic Ocean compared to the closer Sardinian population or the other western Mediterranean populations. Pelagic populations show high mobility and fluid social structure and would tend therefore to show high genetic variability and low population differentiation. Given the geographical location of Lampedusa Island, in the middle of the Strait of Sicily and on the Tunisian continental shelf, the inter-mixing with neighbouring populations inhabiting waters of the Atlantic ocean would not be surprising.

In addition to being possibly affected by geographical isolation and genetic divergence (Wang et al., 1995; Rendell et al., 1999), whistle variations can also reflect habitat condition and/or adaptation to the acoustic environment (Wang et al., 1995; Jones \& Sayigh, 2002; Morisaka et al., 2005; Baron et al., 2008). Acoustic transmission characteristics vary tremendously in shallow water, as they are influenced by numerous environmental factors such as water depth, currents, temperature variation and stratification (Richardson et al., 1995), as well as obstacles that can drastically limit the active range of the underwater signal. In such an environment, the lower frequency parts of a whistle contour are more likely transmitted further than the higher frequency parts in modulated whistles. This can be the case of the Croatian population where the features of the environment could have contributed to shaping whistles towards lower frequency signals. In addition, anthropogenic noise inputs have been proved to influence dolphin vocalisation parameters and behaviour (Morisaka et al., 2005; Baron et al., 2008; La Manna et al., 2013; Papale et al., 2015, 2016; Rako Gospić \& Picciulin, 2016). It has already been demonstrated that common bottlenose dolphins in Lampedusa reacted to boat noise by increasing frequency parameters, only when the boat was a trawler, while recreational boats did not elicit significant increments (La Manna et al., 2013). Furthermore, in the presence of motor boats dolphins preferred to leave the area as the disturbance became too heavy to be tolerated (La Manna et al., 2013). Rako-Gospić et al. (2016) in Croatia found an increase of dolphin whistle frequencies in conditions of high low-frequency noise $(0-2 \mathrm{kHz})$ and a reduction at lower frequencies in conditions of high noise across $2-20 \mathrm{kHz}$ frequency range. Although no data are available in order to compare the absolute levels of Sea Ambient 
Noise (SAN), due to the absence of calibration in the Lampedusa acoustic recorder, the main source of anthropogenic noise for the three areas is recreational boat traffic. Even if boat traffic in the three areas was measured with different sampling protocol, it can be assumed that the mean number of boats in summer are at similar levels (La Manna et al., 2010, 2016; Rako-Gospić et al., 2013). Furthermore, SAN in Croatia seems comparable to the busiest parts of the West Sardinia (La Manna et al., 2016). A relatively comparable background noise can be therefore hypothesised in the studied areas. The shift of frequencies observed in Croatia and Sicily in the presence of boats may explain the difference of about $1-2 \mathrm{kHz}$ where this type of noise dominates. Nevertheless an additional mean difference of about $3-4 \mathrm{kHz}$ was found in the present study between Sicily/Sardinia and Croatia frequency whistle parameters, suggesting that the acoustic environment cannot account alone for the differences observed between the populations of Croatia and Sicily/Sardinia.

In conclusion, our results represent a contribution in identifying acoustically divergent populations of common bottlenose dolphin in the Mediterranean Sea. Nevertheless, further investigations are required in order to isolate those factors (genetic, geographical isolation, behaviour, group structure, noise level, presence of boats) influencing the reported variability in whistle structures and increase our understanding of why such a wide variability was observed between the western and eastern Mediterranean Sea.

\section{Acknowledgements}

Part of this research was partially carried out under the auspices of LIFE NAT/IT000163, between 2005 and 2006, and by National Foundation for Civil Society Development, Croatia. We want to thanks Dr. Gianni Pavan and Prof. Cristina Giacoma for the scientific supervision of the Life project. Special thanks to CTS Ambiente, Nauta and Progetto Natura for their financial and logistic support. We wish to thank Giulia Ceccherelli (University of Sassari) and Francois-Xavier Dechaume-Moncharmont (Universitè de Bourgogne) who provided useful comments and suggestions on the statistical analysis. The authors also thank all the volunteers and students for their assistance and help in the fieldwork, particularly Fabio Ronchetti, Francesco Perretti, Claudia Pitoni, Maja Nimak-Wood and Grgur Pleslić. Special thanks to Andrew Scogliamiglio and Peter Mackelworth for fine-tuning the English. 


\section{References}

Azevedo, F.A., Oliveira, A.M., Dalla Rosa, L. \& Lailson-Brito, J. (2007). Characteristics of whistles from resident bottlenose dolphins (Tursiops truncatus) in southern Brazil. J. Acoust. Soc. Am. 121: 2978-2983.

Azzolin, M., Gannier, A., Lammers, M.O., Oswald, J.N., Papale, E., Buscaino, G., Buffa, G., Mazzola, S. \& Giacoma, C. (2014). Combining whistle acoustic parameters to discriminate Mediterranean odontocetes during passive acoustic monitoring. - J. Acoust. Soc. Am. 135: 502-512.

Baron, S.C., Martinez, A., Garrison, L.P. \& Keith, E.O. (2008). Differences in acoustic signals from delphinids in the western North Atlantic and northern Gulf of Mexico. - Mar. Mamm. Sci. 24: 42-56.

Benmessaoud, R., Cherif, M. \& Kouched, W. (2016). Comparison of habitat use of bottlenose dolphin (Tursiops truncatus) and short beaked common dolphin (Delphinus delphis) in Tunisian northeastern coasts. - In: Report of the 1st international workshop conservation and research networking on short-beaked common dolphin Delphinus delphis in the Mediterranean Sea. Ischia Island, Italy, 13-15 April 2016, p. 23.

Caldwell, M.C., Caldwell, D.K. \& Tyack, P.L. (1990). A review of the signature-whistle hypothesis for the Atlantic bottlenose dolphin. - In: The bottlenose dolphin (Leatherwood, S. \& Reeves, R.R., eds). Academic Press, New York, NY, p. 199-233.

Cañadas, A. \& Hammond, P. (2008). Abundance and habitat preferences of the short-beaked common dolphin Delphinus delphis in the southwestern Mediterranean: implications for conservation. - Endang. Species. Res. 4: 309-331.

Dechaume-Moncharmont, F.X., Monceau, K. \& Cezilly, F. (2011). Sexing birds using discriminant function analysis: a critical appraisal. — Auk. 128: 78-86.

Delarue, J., Todd, S.K., VanParijs, S.M. \& Di Iorio, L. (2009). Geographic variation in Northwest Atlantic fin whale (Balaenoptera physalus) song: implications for stock structure assessment. - J. Acoust. Soc. Am. 125: 1774-1782.

Díaz Lopez, B. (2011). Whistle characteristics in free-ranging bottlenose dolphins (Tursiops truncatus) in the Mediterranean Sea: influence of behaviour. — Mamm. Biol. 76: 180189.

Flury, B. (1988). Common principal components and related multivariate models. - Wiley, New York, NY.

Fortuna, C.M. (2006). Ecology and conservation of bottlenose dolphins (Tursiops truncatus) in the north-eastern Adriatic Sea. — PhD thesis, University of St. Andrews, Scotland, 256 pp.

Gannier, A. (2016). Distribution and habitat of Delphinus delphis in the Mediterranean Sea as obtained from small boat dedicated surveys. - In: Report of the 1st international workshop conservation and research networking on short-beaked common dolphin Delphinus delphis in the Mediterranean Sea. Ischia Island, Italy, 13-15 April 2016, p. 27-28.

Gaspari, S., Scheinin, A., Holcer, D., Fortuna, C., Natali, C., Genov, T., Frantzis, A., Chelazzi, G. \& Moura, A.E. (2015). Drivers of population structure of the bottlenose dolphin (Tursiops truncatus) in the Eastern Mediterranean Sea. - Evol. Biol. 42: 177. 
Gnone, G., Bellingeri, M., Dhermain, F., Nuti, S., Bedocchi, D., Moulins, A., Rosso, M., Alessi, J., McCrea, R.S., Azzellino, A., Airoldi, S., Portunato, N., Laran, S., David, L., Di Meglio, N., Bonelli, P., Montesi, G., Trucchi, R., Fossa, F. \& Wurtz, M. (2011). Distribution, abundance, and movements of the bottlenose dolphin (Tursiops truncatus) in the Pelagos Sanctuary MPA (north-west Mediterranean Sea). — Aquat. Conserv: Mar. Freshw. Ecosyst. 21: 372-388.

Heiler, J., Elwen, S.H., Kriesell, H.J. \& Gridley, T. (2016). Changes in bottlenose dolphin whistle parameters related to vessel presence, surface behaviour and group composition. - Anim. Behav. 117: 167-177.

Hoffman, J.M., Ponnampalam, L.S., Araújo, C.C., Wang, J.Y., Kuit, S.H. \& Hung, S.K. (2015). Comparison of Indo-Pacific humpback dolphin (Sousa chinensis) whistles from two areas of western Peninsular Malaysia. - J. Acoust. Soc. Am. 138: 2829-2835.

Janik, V.M. \& Sayigh, L.S. (2013). Communication in bottlenose dolphins: 50 years of signature whistle research. - J. Comp. Physiol. A 199: 479.

Janik, V.M. \& Slater, P.J.B. (2000). The different roles of social learning in vocal communication. - Anim. Behav. 60: 1-11.

Jones, G.J. \& Sayigh, L.S. (2002). Geographic variation in rates of vocal production of freeranging bottlenose dolphins. - Mar. Mamm. Sci. 18: 374-393.

La Manna, G., Clò, S., Papale, E. \& Sarà, G. (2010). Boat traffic in Lampedusa waters (Strait of Sicily, Mediterranean Sea) and its relation to the coastal distribution of common bottlenose dolphin (Tursiops truncatus). — Cienc. Mar. 36: 71-81.

La Manna, G., Manghi, M., Pavan, G., Lo Mascolo, F. \& Sarà, G. (2013). Behavioural strategy of common bottlenose dolphins (Tursiops truncatus) in response to different kinds of boats in the waters of Lampedusa Island (Italy). - Aquat. Conserv: Mar. Freshw. Ecosyst. 23: 745-757.

La Manna, G., Manghi, M., Perretti, F. \& Sarà, G. (2016). Behavioural response of brown meagre (Sciaena umbra) to boat noise. — Mar. Poll. Bull. 110: 324-334.

Luís, A.R., Couchinho, M.N. \& dos Santos, M.E. (2014). Changes in the acoustic behavior of resident bottlenose dolphins near operating vessels. — Mar. Mamm. Sci. 30: 1417-1426.

May Collado, L.J. \& Wartzok, D. (2008). A comparison of bottlenose dolphin whistles in the Atlantic Ocean: factors promoting whistle variation. - J. Mamm. 89: 1229-1240.

May-Collado, L.J., Agnarsson, I. \& Wartzok, D. (2007). Phylogenetic review of tonal sound production in whales in relation to sociality. - BMC Evol. Biol. 7: 136.

Morisaka, T., Shinohara, M., Nakahara, F. \& Akamatsu, T. (2005). Geographic variations in the whistles among three Indo-Pacific bottlenose dolphin Tursiops aduncus populations in Japan. — Fish. Sci. 71: 568-576.

Moron, J.R., Amorim, T.O., Sucunza, F., de Castro, F.R., Rossi-Santos, M. \& Andriolo, A. (2015). Spinner dolphin whistle in the Southwest Atlantic Ocean: is there a geographic variation? - J. Acoust. Soc. Am. 138: 2495-2498.

Natoli, A., Birkun, A., Aguilar, A., Lopez, A. \& Rus Hoelzel, A. (2005). Habitat structure and the dispersal of male and female bottlenose dolphins (Tursiops truncatus) based on microsatellite and mitochondrial DNA analyses. - Proc. Roy. Acad. Sci. Lond. B: Biol. Sci. 272: 1217-1226. 
Notarbartolo di Sciara, G. \& Demma, M. (1994). Guida dei mammiferi marini del Mediterraneo. - Franco Muzzio, Padua.

Pace, D.S., Mussi, B., Airoldi, S., Alessi, J., Arcangeli, A., Atzori, F., Azzolin, M., Campana, I., Celona, A., Fiori, C., Giacoma, C., Gnone, G., Luperini, C., Mangano, R., Miragliuolo, A., Moulins, A., Nuti, S., Pellegrino, G., Rosso, M., Salvioli, F., Tepsich, P. \& Tringali, M. (2015). New insights on the presence and distribution of the endangered short-beaked common dolphin Delphinus delphis in Italian waters. — Biol. Mar. Med. 22: 262-263.

Papale, E., Azzolin, M., Cascao, I., Gannier, A., Lammers, M.O., Martin, V.M., Oswald, J., Perez-Gil, M., Prieto, R., Silva, M.A. \& Giacoma, C. (2014). Acoustic divergence between bottlenose dolphin whistles from the Central-Eastern North Atlantic and Mediterranean Sea. - Acta Ethol. 17: 155-165.

Papale, E., Gamba, M., Perez-Gil, M., Martin, V.M. \& Giacoma, C. (2015). Dolphins adjust species-specific frequency parameters to compensate for increasing background noise. PLoS ONE 10: e0121711.

Pleslić, G., Rako Gospić, N., Mackelworth, P., Wiemann, A., Holcer, D. \& Foruna, C.M. (2015). The abundance of common bottlenose dolphins (Tursiops truncatus) in the former special marine reserve of the Cres-Lošinj Archipelago, Croatia. - Aquat. Conserv: Mar. Freshw. - Ecosyst. 25: 125-137.

Pulcini, M., Fortuna, C.M., La Manna, G., Triossi, F. \& Pace, D.S. (2010). GIS spatial analysis as management tool to describe the habitat use of bottlenose dolphins in the Lampedusa waters (Italy): results from eleven years of observation. - In: 24th annual conference of the European Cetacean Society, 22-24 March 2010. Stralsund (CD-ROM).

Pulcini, M., Pace, D.S., La Manna, G., Triossi, F. \& Fortuna, C.M. (2013). Distribution and abundance estimates of bottlenose dolphins (Tursiops truncatus) around Lampedusa Island (Sicily Channel, Italy) — implications for their management. — J. Mar. Biol. Ass. UK 94: 1175-1184.

Quick, N.J. \& Janik, V.M. (2008). Whistle rates of wild bottlenose dolphins (Tursiops truncatus): influences of group size and behavior. — J. Comp. Psychol. 122: 305-311.

Rako Gospić, N. \& Picciulin, M. (2016). Changes in whistle structure of resident bottlenose dolphins in relation to underwater noise and boat traffic. - Mar. Poll. Bull. 105: 193-198.

Rako Gospić, N., Fortuna, C.M., Holcer, D., Mackelworth, P., Nimak-Wood, M., Pleslić, G., Sebastianutto, L., Vilibić, I., Wiemann, A. \& Picciulin, M. (2013). Leisure boating noise as a trigger for the displacement of the bottlenose dolphins of the Cres-Lošinj archipelago (northern Adriatic Sea, Croatia). - Mar. Poll. Bull. 68: 77-84.

Rendell, L.E., Matthews, J.N., Gill, A., Gordon, J.C.D. \& Macdonald, D.W. (1999). Quantitative analysis of tonal calls from five odontocete species, examining interspecific and intraspecific variation. - J. Zool. Lond. 249: 403-410.

Richardson, W.J., Greene, C.R., Malme, C.I. \& Thomson, D.H. (1995). Marine mammals and noise. - Academic Press, San Diego, CA.

Riesch, R., Ford, J.K.B. \& Thomsen, F. (2006). Stability and group specificity of stereotyped whistles in resident killer whales, Orcinus orca, off British Columbia. - Anim. Behav. 71: 79-91. 
Rossi dos Santos, M.E., Louro, S., Couchinho, M. \& Brito, C. (2005). Whistles of bottlenose dolphins (Tursiops truncatus) in the Sado Estuary, Portugal: characteristics, production rates, and long-term contour stability. - Aquat. Mamm. 31: 453-462.

Rossi-Santos, M.R. \& Podos, J. (2005). Latitudinal variation in whistle structure of the estuarine dolphin Sotalia guianensis. - Behaviour 143: 347-364.

Schultz, K.W. \& Corkeron, P.J. (1994). Interspecific differences in whistles produced by inshore dolphins in Moreton Bay, Queensland, Australia. — Can. J. Zool. 72: 1061-1068.

Steiner, W.W. (1981). Species-specific differences in pure tonal whistle vocalizations of five western North Atlantic dolphin species. — Behav. Ecol. Sociobiol. 9: 241-246.

Wang, D.W., Würsig, B. \& Evans, W.E. (1995). Whistles of bottlenose dolphins: comparisons among populations. - Aquat. Mamm. 21: 65-77. 